\title{
Immediate Small-Diameter Implants as Abutments for an Overdenture in the Edentulous Atrophic Mandible: Report of Immersion Endoscopic Bone in vivo, and Histologic Bone-Implant Evaluation After 6 Months of Function
}

\author{
Implantes de Pequeño Diámetro como Soporte Inmediato de Sobredentaduras \\ en Hueso Alveolar Mandibular Atrófico: Reporte de Endoscopía de Inmersion \\ in vivo y Evaluación Histológica a los 6 Meses de Función
}

Víctor Beltrán ${ }^{1,3}$; Ricardo Lillo²; Benjamín Weber³; Iván Valdivia-Gandur; María Cristina Manzanares-Céspedes ${ }^{5} \&$ Wilfried Engelke ${ }^{6,7}$

BELTRÁN, V.; LILLO, R.; WEBER, B.; VALDIVIA-GANDUR, I.; MANZANARES-CÉSPEDEZ, M. C. \& ENGELKE, W. Immediate small-diameter implants as abutments for an overdenture in the edentulous atrophic mandible: report of immersion endoscopic bone in vivo, and histologic bone-implant evaluation after 6 months of function. Int. J. Morphol., 37(2):452-458, 2019.

SUMMARY: The aim of this report was to endoscopically evaluate bone quality in vivo in the immediate installation of temporary small-diameter implants, and again after 6 months of function, through an attachments system for overdenture, in the atrophic mandible of a patient. We also histologically evaluated bone-implant interaction in these temporary small-diameter implants, once the success of the osseointegration of the submerged implants was guaranteed. A patient received a total of 6 implants in the atrophic mandible, two of which were immediately loaded with a provisional prosthesis, and four were left to heal in a submerged way. Further, an immersion endoscopic evaluation was performed during bone drilling, and this showed a compact bone structure with limited vascularization and predominantly cortical structure. This immediate loading protocol involving an overdenture retained by two small-diameter implants of $2.9 \mathrm{~mm}$ in the atrophic mandible proved to be successful after 6 months of loading. Clinical and histologic osseointegration was consistently achieved for both of the retrieved immediately loaded implants. This modality allows the patient to be restored with a stable, functional, and aesthetic prosthesis during the osseointegration period of submerged implants and soft-tissue healing, before the removal of the provisional implants. The histological evaluation of bone-implant contact found that the space between the implant threads closer to the surface was filled with woven bone and lamellar bone, but the tissue in contact with the cervical portion of the implants was compatible with cortical bone organization. Also, the newly formed bone has a regular cell distribution and characteristics of advanced maturation after 6 months of function in the atrophic mandible. Anchored overdentures in 2 to 4 small-diameter implants ( $2.9 \mathrm{~mm})$ for edentulous patients with severe atrophy of the mandible with cortical bone would be a minimally invasive alternative.

KEY WORDS: Overdentures; Osseointegration; Small-diameter implants; Edentulous; Endoscopy.

\section{INTRODUCTION}

Small-diameter implants, narrow-diameter implants, and mini-dental implants are all names used to describe implants with diameters less than $3.5 \mathrm{~mm}$. These implants provide a real alternative to the horizontal augmentation techniques in severe bone atrophy situations (Sohrabi et al., 2012). The lack of width and height of the osseous tissue is considered an obstacle in the selection of cases for prosthetic rehabilitation with dental implants (Calvo-Guirado et al., 2014). In this sense, the use of small-diameter implants represents an easy therapeutic alternative in routine implantology, especially for patients who have reduced jaw bone dimensions.

\footnotetext{
${ }^{1}$ CIDIC, Faculty of Dentistry, Universidad de La Frontera, Temuco, Chile.

${ }^{2}$ Postgraduate Program in Oral Implantology, School of Dentistry, Science Faculty Universidad Mayor, Santiago, Chile.

${ }^{3}$ Postgraduate Program in Oral Rehabilitation, School of Dentistry, Faculty of Dentistry, Universidad de La Frontera, Chile.

${ }^{4}$ Biomedical and Dentistry Departments, Universidad de Antofagasta, Antofagasta, Chile.

${ }^{5}$ Experimental Pathology and Therapeutics Department, Universitat de Barcelona, Barcelona, Spain.

${ }^{6}$ Department of Oral and Maxillofacial Surgery, Center for Dentistry, Oral Medicine and Craniomaxillofacial Surgery, University of Göttingen, Göttingen, Germany. ${ }^{7}$ Center of Physics and Engineering in Medicine (CFIM), Faculty of Engineering and Sciences, Universidad de La Frontera, Temuco, Chile.
} 
BELTRÁN, V.; LILLO, R.; WEBER, B.; VALDIVIA-GANDUR, I.; MANZANARES-CÉSPEDEZ, M. C. \& ENGELKE, W. Immediate small-diameter implants as abutments for an overdenture in the edentulous atrophic mandible: report of immersion endoscopic bone in vivo, and histologic bone-implant evaluation after 6 months of function. Int. J. Morphol., 37(2):452-458, 2019.

Bone quantity and quality often determine whether a standard implant can be placed. A reduced bucco-lingual dimension (< $4 \mathrm{~mm}$ in width) does not allow the placement of a standard-diameter implant without increasing the risk of "implant threads" exposure (Romeo et al., 2006) Therefore, surgical planning with small-diameter implants in the atrophic jaw can be a minimally invasive alternative and quick solution for the patient.

In addition, patients with mandibular overdentures retained by small-diameter implants can significantly improve the quality of life compared with patients with conventional prostheses (Jofre et al., 2013).

Another application of small-diameter implants is to use these as temporary implants, which allows patients to use an implant-retained prosthesis immediately after surgery, giving them function and aesthetics similar to the final treatment.

An additional advantage of using temporary implants at the same time of submerged implants is that, in the event that immediately loaded temporary implants fail during the interim period, a sufficient number of submerged implants will still support the final implant-supported rehabilitation (Shnitman et al., 1990). Another advantage of immediate provisional implants in the edentulous atrophic mandible is that the abutments for the overdenture act as a diagnostic prosthesis (Ravasini \& Marinello, 2002).

The aim of this report was to endoscopically evaluate bone quality in vivo in the immediate installation of temporary small-diameter implants, and again after 6 months of function, through an attachments system for overdenture, in the atrophic mandible of a patient. We also histologically evaluated bone-implant interaction in these temporary smalldiameter implants, once the success of the osseointegration of the submerged implants was guaranteed.

\section{MATERIAL AND METHOD}

Case Description. The patient agreed to the protocol and signed an informed consent. This study was approved by the scientific ethics committee at the Universidad Mayor, Chile.

Surgical Protocol. The patient was a 62-year-old nonsmoker who had advanced resorption of the mandible (Fig. 1A), which is characterized by a knife edge and small dimensions of the alveolar ridge $(<4 \mathrm{~mm}$ in the crestal alveolar ridge and $<5-\mathrm{mm}$ basal $\mathrm{rim}$ ) measured by a bone caliper. Immediate loading protocol was performed, following the concept of Schnitman et al. (1990), which involves the simultaneous placement of submerged and immediate loading implants in the edentulous lower jaw. In this protocol, immediate load implants must hold and retain a temporary acrylic prosthesis through an overdenture fixation system, so that submerged implants can be osseointegrated in the traditional way.

The reason for placement of the submerged implants is that if the immediately loaded implants fail during the interim period, we will have a sufficient number of submerged implants to support the final implant-supported rehabilitation.

To this end, it was proposed that the patient receive 4 submerged implants, 2 implants of 3.75-mm diameter and $15 \mathrm{~mm}$ in length (Titamax Cortical CM, Curitiba, Brazil) and 2 implants of $2.9 \mathrm{~mm}$ diameter and $12 \mathrm{~mm}$ in length (Facility Neodent, Curitiba, Brazil). The planning was subject to the reduced size of the mandibular rim. A surgical guide was used, which was drawn up by a transparent acrylic prosthesis replica. The guide was composed of metal tubes to guide the initial osteotomy, creating a path for the drills. Two further reduced diameter implants of $2.9 \mathrm{~mm}$ in diameter and $12 \mathrm{~mm}$ in length (Facility Neodent, Curitiba, Brazil) in the anterior mandible were immediately loaded with a provisional acrylic prosthesis by an overdenture attachment system. The bone density of bone cavities prior to installing the provisional implants were tested "in vivo" by immersion endoscopic technique (Fig. 1B) (Engelke, 2002; Beltrán et al., 2012).

All implants displayed a high degree of primary stability, requiring a greater than $32 \mathrm{Ncm}$ torque as tested with a torque control instrument (Fig. 1C). The soft tissues were sutured over the four submerged implants and around the two protruding abutments.

After surgery, the patient was instructed to follow a semi-soft diet for 7 to 10 days and to use chlorhexidine 0.12 $\%$ mouthwashes for 14 days. Follow-up visits were scheduled for 1,3 , and 8 weeks after the procedure.

After 6 months of occlusal function of the provisional prosthesis, a gingival flap was made to discover the 4 submerged implants to be connected to the final prosthesis by abutments for overdentures. The two additional provisory implants were retrieved by a $3.5 \mathrm{~mm}$ diameter trephine. Care was taken to avoid altering the lingual and vestibular cortex at the implant sites. Clinical mobility was assessed, showing that all of the immediately loaded and submerged implants had achieved clinical osseointegration. 
Subsequently, each sample (implant with its bone segment) was fixed in $10 \%$ neutral buffered formaldehyde for 48 hours. Afterward, the samples were processed for their inclusion in light-curing resin (Technovit $®)$. In the next step, the samples were cut following the central longitudinal axis of implant by an Exact@ diamond band saw (0.2-mm thick) and conditioned for back scattering scanning electron microscope (BS-SEM) analysis following a procedure described in the literature (Manzanares et al., 1997; Franch et al., 2000). The microscopic analysis and image collection for structural analysis were performed in Scientific and Technical Services of the University of Barcelona, Spain. The images were obtained by the INCA® Microanalysis system.

In vivo Endoscopic evaluation of implant bone cavities. For an edentulous jaw, the drilling protocol was performed following the manufacturer's recommendations for dense bone (Facility Neodent, Curitiba, Brazil), and the implant was inserted through the ratchet wrench torque until half of its length, and then it was removed and temporarily kept in the glass container to allow endoscopic evaluation of bone preparations before implantation and verify the integrity of the bone cavity and the characteristics of bone tissue in vivo under high magnification. After this, the implant was installed throughout its length.

The endoscopic equipment used consisted in a 1.9$\mathrm{mm}$ diameter optical with continuous internal saline irrigation and a $300 \mathrm{~W}$ light source with a capacity of 6000 $\mathrm{K}$ connected to a video monitor (Karl Storz, Tuttlingen, Germany). After the endoscopic assessment to rule out fenestrations or intraalveolar fractures, implant installation was completed. Three of the four reduced-diameter implants were installed slightly below the level of the jawbone. The other one was installed $1 \mathrm{~mm}$ above the bone level. The provisional implant placement was performed with a reducing hand piece on low speed (25-30 rpm), and the last $2 \mathrm{~mm}$ of the implant were inserted manually with a hand wrench to ensure primary stability facilitated by the cylindrical body of the implant. All implants reached an insertion torque of at least $32 \mathrm{Ncm}$ tested with a torque instrument. One of the small-diameter implants was placed $1 \mathrm{~mm}$ above bone level to prevent excessive power in their installation and prevent fracture lines at the crestal alveolar ridge.

Immersion endoscopic evaluation of all bone cavities showed a compact structure with limited vascularization and predominantly cortical structure (Figs. 2A-C). There were no fenestrations, fractures, or foreign particles detected during endoscopic inspection (Table I).

Histologic Evaluation. A histologic evaluation was performed on two immediately loaded implants retrieved after 6 months of function. The interaction formed between bone tissue and the mini-implant surface is shown in Figure 3 . The space between the implant threads close to the surface was filled with woven bone ( $\mathrm{Wb}$ ) and lamellar bone (Lb). In this area, the tissue is compatible with the cortical bone organization (Section A, Fig. 3). This newly formed bone has a regular cell distribution and characteristics of advanced maturation. Moreover, to the depth it was observed, several bone trabecular and medullar spaces were in contact with the implant surface (Section B, Fig. 3). Close to the trabecular, we observed several vascular spaces from approximately 70 to $150 \mathrm{~mm}$ that represented blood vessels. Remodeled activity was observed, presumably depending on the forces applied to the implant. Some vascular spaces showed lamellar bone around them. In general, the bone exhibited a tendency toward the mature osseous tissue.

Table I. Description of the small implants retrieved with surrounding tissue and endoscopic inspection of implant cavities.

\begin{tabular}{|c|c|c|c|c|}
\hline $\begin{array}{c}\text { Small-Diameter } \\
\text { Implant }\end{array}$ & Load Type & $\begin{array}{l}\text { Immersion endoscopic } \\
\text { evaluation in vivo }\end{array}$ & $\begin{array}{l}\text { Histologic } \\
\text { Evaluation }\end{array}$ & Observations \\
\hline Zone 3.2 Implant & $\begin{array}{l}\text { Immediate } \\
\text { loading }\end{array}$ & $\begin{array}{l}\text { Compact bone structure with } \\
\text { limited vascularization }\end{array}$ & Yes & $\begin{array}{l}\text { Implants were recovered at } 6 \text { months. No } \\
\text { complications were observed }\end{array}$ \\
\hline Zone 4.2 Implant & $\begin{array}{l}\text { Immediate } \\
\text { loading }\end{array}$ & $\begin{array}{l}\text { Compact bone structure with } \\
\text { limited vascularization }\end{array}$ & Yes & $\begin{array}{l}\text { During placement, implant was left } 1 \mathrm{~mm} \\
\text { above bone level and was recovered at } 6 \\
\text { months. No complications were observed. }\end{array}$ \\
\hline Zone 3.3 Implant & Submerged & $\begin{array}{l}\text { Compact bone structure with } \\
\text { limited vascularization }\end{array}$ & No & $\begin{array}{l}\text { The implant was located at } 6 \mathrm{~m} \text { onths and } \\
\text { connected to the final prosthesis. No } \\
\text { complications were observed. }\end{array}$ \\
\hline Zone 4.3 Implant & Submerged & $\begin{array}{l}\text { Compact bone structure with } \\
\text { limited vascularization }\end{array}$ & No & $\begin{array}{l}\text { The implant was located at } 6 \mathrm{~m} \text { onths and } \\
\text { connected to the final prosthesis. No } \\
\text { complications were observed. }\end{array}$ \\
\hline
\end{tabular}




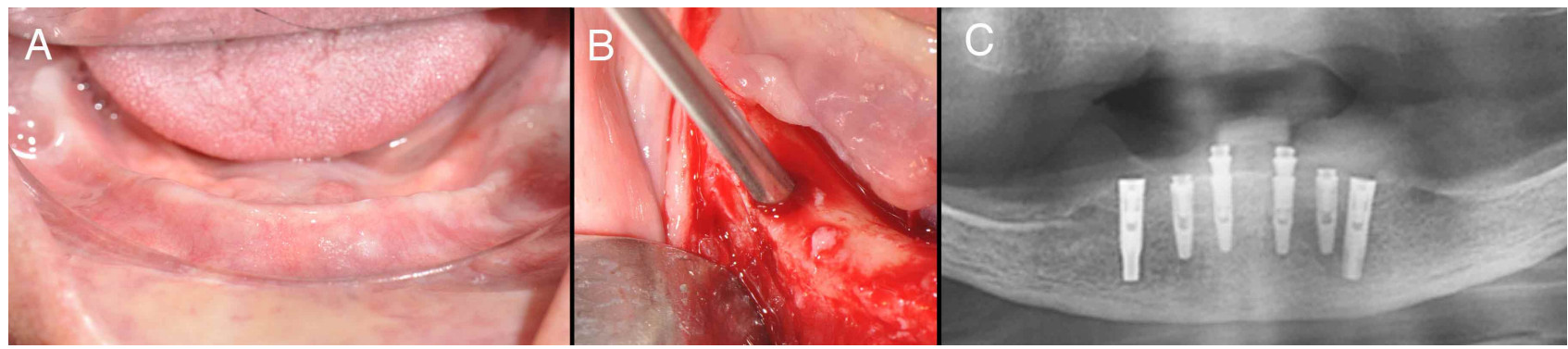

Fig. 1. A. Preoperative view of edentulous jaw with advanced atrophy; B. Immersion endoscopic control during osteotomy preparation before implant installation; C. Radiographic control after implant installation in the anterior portion of the mandible. Note that the two implants of 2.9-mm diameter in mesial position were connected by an attachment system for overdenture to support a temporary acrylic prosthesis for 6 months.

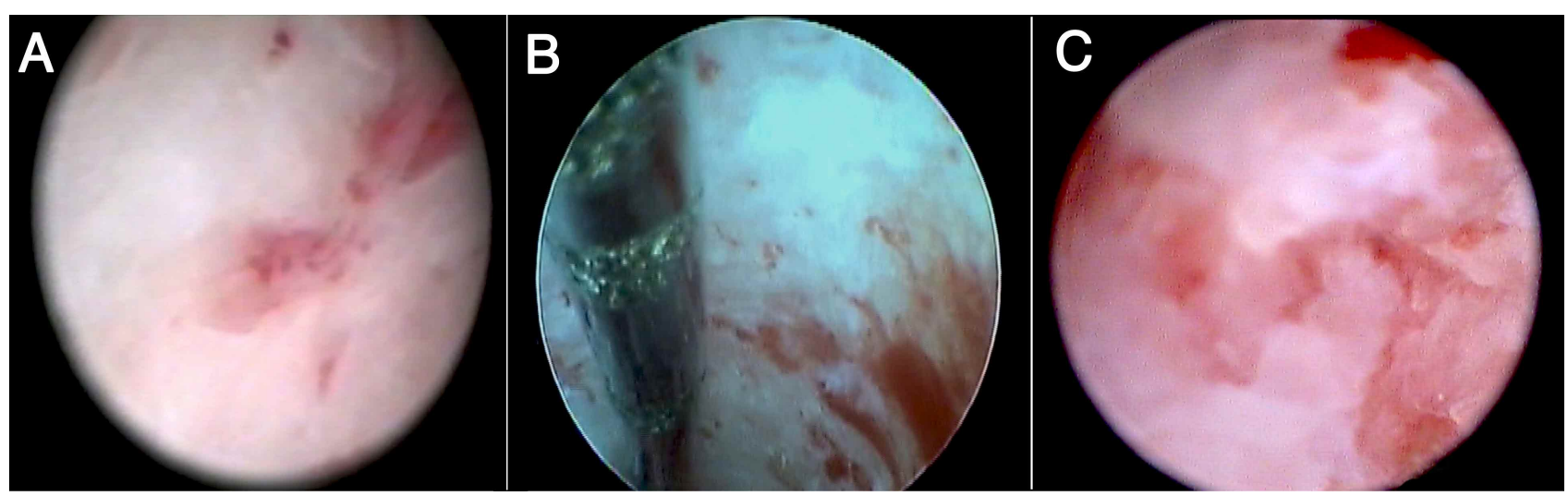

Fig. 2. Endoscopic inspections of implant cavities by immersion endoscopy. A. High bone density without active bleeding at the base of the cavity; B. Probing simultaneous buccal bone wall demonstrates a predominantly compact bone structure with limited vasculature from the vascular channels; C. Flat bed with high bone density and few vascular elements.

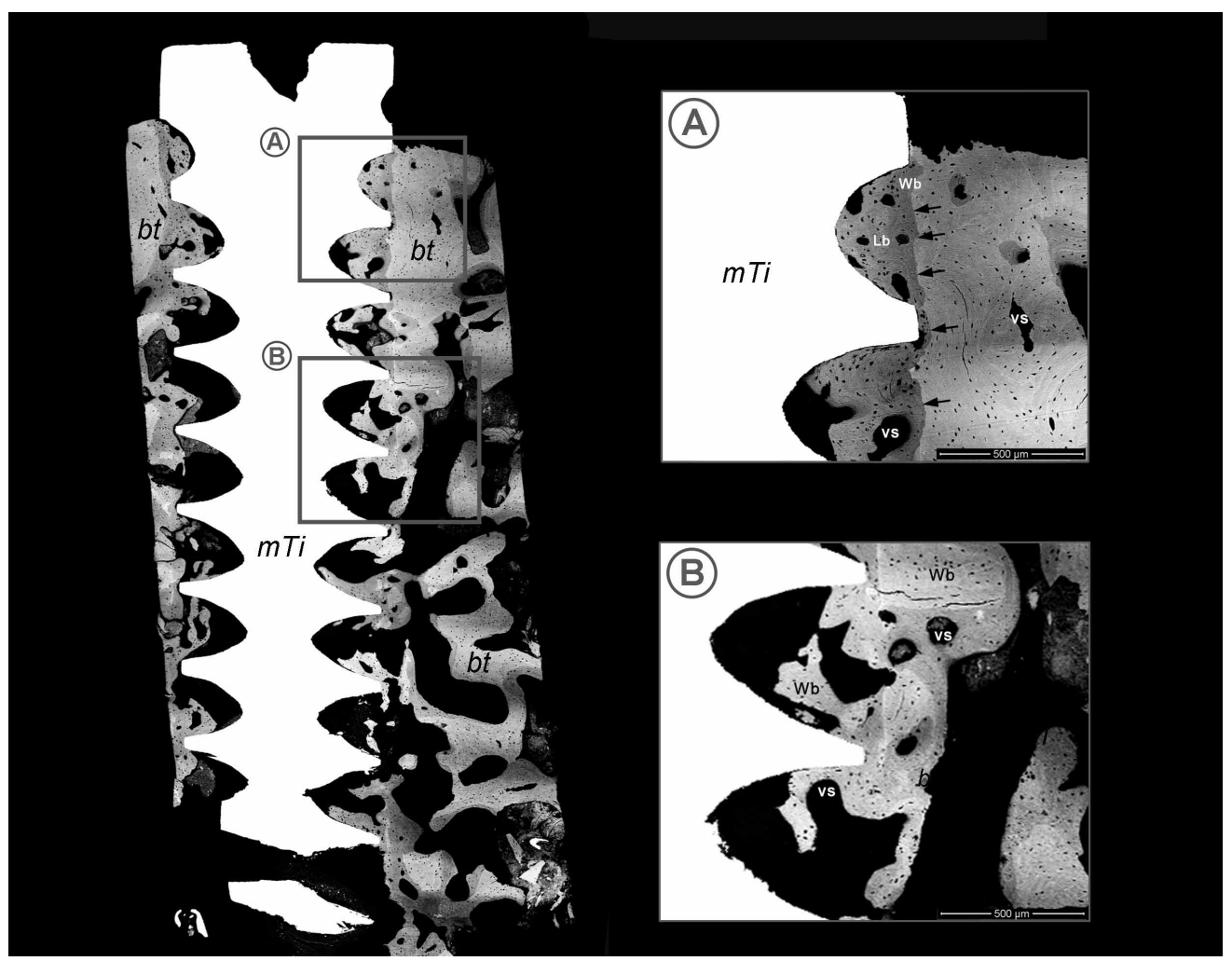

Fig. 3. In the image, bone tissue formed around the mini-implant surface analyzed by backscattering electron microscopy. Black arrows show the boundary between old bone and newly bone formed around the mini-implant. Section A: Cortical bone; Section B: Trabecular bone. Wb: woven bone; Lb: lamellar bone bt: bone tissue; mTi: mini titanium implant; Vs: vascular space. 
BELTRÁN, V.; LILLO, R.; WEBER, B.; VALDIVIA-GANDUR, I.; MANZANARES-CÉSPEDEZ, M. C. \& ENGELKE, W. Immediate small-diameter implants as abutments for an overdenture in the edentulous atrophic mandible: report of immersion endoscopic bone in vivo, and histologic bone-implant evaluation after 6 months of function. Int. J. Morphol., 37(2):452-458, 2019.

\section{DISCUSSION}

Implants with small diameters can be used successfully in a variety of clinical situations. Less surgical time, less postoperative pain, ability of direct loading after surgery with no harm to bone, and cost effectiveness are the advantages, but special cautions of bone quality and good oral hygiene should be maintained (Gleiznys et al., 2012). A literature review showed that survival rates reported for small-diameter implants are similar to those reported for standard width implants, and these survival rates did not appear to differ between studies that used flapless or flap reflection techniques. However, the failure rate appeared to be higher in shorter small-diameter implants than in longer ones in the studies in which the length of the failed implants was reported (Sohrabi et al.). A 5-year retrospective study concluded that the use of small-diameter implants of $3.3 \mathrm{~mm}$ after the standard healing period (3-6 months) appears to be predictable if clinical guidelines are followed and appropriate prosthetic restorations are provided. However, it should be noted that fatigue fracture might occur (Yaltirik et al., 2011).

An in vitro study found that implant material and the implant-abutment connection design significantly influence the peri-implant bone strain of immediately loaded small-diameter implants, but barely affect their primary stability (Wu et al., 2014). Regarding the influence of design of small-diameter implants in the narrow alveolar ridge, a recent experimental study in dogs demonstrated that the design of the narrow implants plays an important role in peri-implant mucosa and crestal bone maintenance at the 8-week follow-up (Calvo-Guirado et al.) A longitudinal study of 1 to 7 years follow-up reported that standard and narrow implant prognoses are influenced by peri-implant bone infection more than biomechanical factors, such as implant overloading (Romeo et al.).

Ravasini \& Marinello used 3 titanium alloy provisional implants (Ti-6Al-4V) in the interforaminal area of an edentulous jaw, and 4 implants of conventional diameter (Bränemark MK II, Nobel Biocare, CA, USA) were left submerged for the healing period. The provisional prosthesis was retained to provisional implants by a bar that was manufactured using a preformed pattern until approximately 7 months, when the conventional implants were exposed and connected by a ballattachment system. The provisional implants had remained stable and functional during the healing period of the conventional implants and were removed easily 20 days after the connection of the conventional implants.
A double-blind, randomized, controlled trial study concluded that after 36 months, similar outcomes such as bone-level change, soft-tissue parameters, survival, and success were found between Ti Grade IV and TiZr small-diameter implants of $3.3 \mathrm{~mm}$ (Quirynen et al., 2015). In addition, these authors reported that the results seen at 12 months continued over time.

A randomized clinical trial showed that after 1-year follow-up, patients wearing mandibular overdentures with two minimally invasive splinted small-diameter implants of $1.8 \mathrm{~mm}$ and $15 \mathrm{~mm}$ length (Sendax ${ }^{\circledR}$ MDI; IMTEC Corp., Ardmore, OK, USA) experienced more improvements in perceived oral health-related quality of life than patients having conventional treatment (Jofre et al.). These authors recommend the use a surgical guide to control the precise insertion of the implant into the jawbone when working blind with a flapless procedure. In our study, we also used surgical guides with strategic tubes by the open flap technique due to the severe mandibular atrophy of the selected patients, and this method improved the direct visualization of possible buccal bone wall fractures or bone dehiscence. Further, in some patients, it was necessary to regularize the ridge by an osteotomy located in the cervical portion of the bone crest. During the placement of temporary implants with 2-mm and 2.8-mm diameters, some authors recommend using a low speed hand piece (20-25 rpm), and the last $2 \mathrm{~mm}$ of the implant must be inserted manually using a hand wrench to achieve primary stability (Ravasini \& Marinello). In our case, we perform the placement of Facility 2.9-mm diameter implants (Facility, Neodent, Brazil) at low speed (25-30 rpm) using the surgical motor up to $2 / 3$ of the length; the last $1 / 3$ is inserted manually to achieve better stability through the implant design, which has some self-tapping capacity that allows great adaptability in the cortical bone. Regarding bone quality, some authors conclude that it is an important prognostic factor for small-diameter implants because the cancellous bone (type 4) can increase implant failures (Romeo et al.). In this sense, the incorporation of immersion endoscopy as a method for "in vivo" diagnosis preparation implant allows a quick check of the bone structure and may be useful for detecting possible accidents during bone preparation.

Histological evaluation of immediately loaded implants in the edentulous mandible found that at 4 months, the bone remodeling was not impeded by these load conditions, and a high level of bone apposition ( $78 \%-85 \%)$ was measured (Testori et al., 2001). These authors propose that the interface consists of a combination of new and old bone, like implants without load, and the load capacity is ensured by a dynamic remodeling of necrotic bone. We used our clinical protocol, similar to that described, which is based on the concept of Schnitman et al. However, these authors 
BELTRÁN, V.; LILLO, R.; WEBER, B.; VALDIVIA-GANDUR, I.; MANZANARES-CÉSPEDEZ, M. C. \& ENGELKE, W. Immediate small-diameter implants as abutments for an overdenture in the edentulous atrophic mandible: report of immersion endoscopic bone in vivo, and histologic bone-implant evaluation after 6 months of function. Int. J. Morphol., 37(2):452-458, 2019.

used a protocol of immediate loading in six implants that had a provisional restoration retained in standard pillars, and our study used only two small-diameter implants for a mucoimplant-supported retention of the provisional prosthesis until the sixth month.

Regarding the response of the interfacial bone and the type of surface treatment of small-diameter implants, a histological study in human implants $3.3 \mathrm{~mm}$ (TSP, Straumann) and $3.5 \mathrm{~mm}$ (SLA, Straumann) in diameter recovered after 5 years showed that it was highly calcified bone, but there were differences in the percentage of boneimplant contact. However, the same authors report that there were differences such as load conditions, time of implantation, implant location, and age and design of the implants between the two implant cases recovered (Hayakawa et al., 2002).

Similarly, in a report of 3.5-mm implant diameter (Ankylos, Dentsply, NY, USA) recovered after 10 years of function, a mature trabecular tissue was observed between the implant threads with a regular cell distribution and lamellar organization of calcified matrix. It was observed that bone tissue followed the shape of the implant's surface with which it was in contact (Fuentes, et al. 2015). Another human histologic study reported that the addition of nanometer-scale $\mathrm{CaP}$ crystals to the dual acid-etched surface of the 2-mm-diameter implants (Osseotite 3i, Miami, FL, USA) appeared to have a significant effect on the development of new bone at 4 and 8 weeks after implant placement, and this may have significant clinical implications in terms of implant placement, with accelerated healing in areas of poor-quality bone (Goené et al., 2007).

Our results showed that the space between implant threads close to the surface was filled with woven bone and lamellar bone, especially the tissue in contact with the cervical portion of the implants, which is compatible with cortical bone organization. The newly formed bone also has a regular cell distribution and characteristics of advanced maturation after 6 months of function in the atrophic mandible. This could be influenced by the implant design, bone quality, and load conditions, but more clinical studies are needed for a better evaluation of small-diameter implants in the mandibular atrophic bone.

Based on this experience, we think a system of anchored overdentures in 2 to 4 small-diameter implants (2.9 $\mathrm{mm}$ ) for edentulous patients with severe atrophy of the mandible with cortical bone would be a minimally invasive alternative. However, clinical designs with larger numbers of patients and long-term follow-up for more reliable results are needed.

\section{ACKNOWLEDGMENTS}

We want to acknowledge ILAPEO (Curitiba, Brazil) for implants support. We also appreciate the collaboration of Implant Clinic of School of Dentistry, Universidad Mayor, Santiago, Chile. This work was supported in part by MINEDUC-UA project, code ANT 1755, MEC Proyect Folio: PAI80160012 CONICY-Chile and Insertion Program DI16-6009, Universidad de La Frontera, Chile.

BELTRÁN, V.; LILLO, R.; WEBER, B.; VALDIVIAGANDUR, I.; MANZANARES-CÉSPEDEZ, M. C. \& ENGELKE, W. Implantes de pequeño diámetro como soporte inmediato de sobredentaduras en hueso alveolar mandibular atrófico: reporte de endoscopía de inmersión in-vivo y evaluación histológica a los 6 meses de función. Int. J. Morphol., 37(2): :452-458, 2019.

SUMMARY: The aim of this report was to endoscopically evaluate bone quality in vivo in the immediate installation of temporary small-diameter implants, and again after 6 months of function, through an attachments system for overdenture, in the atrophic mandible of a patient. We also histologically evaluated bone-implant interaction in these temporary small-diameter implants, once the success of the osseointegration of the submerged implants was guaranteed. A patient received a total of 6 implants in the atrophic mandible, two of which were immediately loaded with a provisional prosthesis, and four were left to heal in a submerged way. Further, an immersion endoscopic evaluation was performed during bone drilling, and this showed a compact bone structure with limited vascularization and predominantly cortical structure.This immediate loading protocol involving an overdenture retained by two small-diameter implants of $2.9 \mathrm{~mm}$ in the atrophic mandible proved to be successful after 6 months of loading. Clinical and histologic osseointegration was consistently achieved for both of the retrieved immediately loaded implants. This modality allows the patient to be restored with a stable, functional, and aesthetic prosthesis during the osseointegration period of submerged implants and soft-tissue healing, before the removal of the provisional implants. The histological evaluation of bone-implant contact found that the space between the implant threads closer to the surface was filled with woven bone and lamellar bone, but the tissue in contact with the cervical portion of the implants was compatible with cortical bone organization. Also, the newly formed bone has a regular cell distribution and characteristics of advanced maturation after 6 months of function in the atrophic mandible. Anchored overdentures in 2 to 4 smalldiameter implants $(2.9 \mathrm{~mm})$ for edentulous patients with severe atrophy of the mandible with cortical bone would be a minimally invasive alternative.

KEY WORDS: Overdentures; Osseointegration; Small-diameter implants; Edentulous; Endoscopy. 


\section{REFERENCES}

Beltrán, V.; Fuentes, R. \& Engelke, W. Endoscopic visualization of anatomic structures as a support tool in oral surgery and implantology. J. Oral Maxillofac. Surg., 70(1):e1-6, 2012.

Calvo-Guirado, J. L.; López-López, P. J.; Mate Sanchez, J. E.; Gargallo Albiol, J.; Velasco Ortega, E. \& Delgado Ruiz, R. Crestal bone loss related to immediate implants in crestal and subcrestal position: a pilot study in dogs. Clin. Oral Implants Res., 25(11):1286-94, 2014.

Engelke, W. G. In situ examination of implant sites with support immersion endoscopy. Int. J. Oral Maxillofac. Implants, 17(5):703-6, 2002.

Franch, J.; Pastor, J.; Franch, B.; Durall, I. \& Manzanares, M. C. Back-scattered electron imaging of a non-vertebral case of hypervitaminosis $\mathrm{A}$ in a cat. J. Feline Med. Surg., 2(1):49-56, 2000.

Fuentes, R.; Valdivia, I.; Borie, E.; Beltran, V. \& Bucchi, C. Histomorphological analysis of peri-implant bone tissue of an implant in use for 10 years: A case report. Biomed. Res. (India), 26(2):384-8, 2015.

Gleiznys, A.; Skirbutis, G.; Harb, A.; Barzdziukaite, I. \& Grinyte, I. New approach towards mini dental implants and small-diameter implants: an option for long-term prostheses. Stomatologija, 14(2):39-45, 2012.

Goené, R. J.; Testori, T. \& Trisi. P. Influence of a nanometer-scale surface enhancement on de novo bone formation on titanium implants: a histomorphometric study in human maxillae. Int. J. Periodontics Restorative Dent., 27(3):211-9, 2007.

Hayakawa, T.; Kiba, H.; Yasuda, S.; Yamamoto, H. \& Nemoto, K. A histologic and histomorphometric evaluation of two types of retrieved human titanium implants. Int. J. Periodontics Restorative Dent., 22(2):164-71, 2002.

Jofre, J.; Castiglioni, X. \& Lobos, C. A. Influence of minimally invasive implant-retained overdenture on patients' quality of life: a randomized clinical trial. Clin. Oral Implants Res., 24(10):1173-7, 2013.

Manzanares, M. C.; Calero, M. I.; Franch, J. \& Serra, I. Optimisation of a scheduled study for undecalcified samples. Microsc. Anal., 50:17-9, 1997.

Quirynen, M.; Al-Nawas, B.; Meijer, H. J.; Razavi, A.; Reichert, T. E.; Schimmel, M.; Storelli, S.; Romeo, E. \& Roxolid Study Group. Smalldiameter titanium Grade IV and titanium-zirconium implants in edentulous mandibles: three-year results from a double-blind, randomized controlled trial. Clin. Oral Implants Res., 26(7):831-40, 2015.

Ravasini, T. \& Marinello, C. P. Immediate provisional implants as abutments for an overdenture in the mandibular edentulous jaw: case presentation. Pract. Proced. Aesthet. Dent., 14(8):673-7, 2002.

Sohrabi, K.; Mushantat, A.; Esfandiari, S. \& Feine, J. How successful are small-diameter implants? A literature review. Clin. Oral Implants Res., 23(5):515-25, 2012

Romeo, E.; Lops, D.; Amorfini, L.; Chiapasco, M.; Ghisolfi, M. \& Vogel, G. Clinical and radiographic evaluation of small-diameter (3.3-mm) implants followed for 1-7 years: a longitudinal study. Clin. Oral Implants Res., 17(2):139-48, 2006.

Schnitman, P. A.; Wohrle, P. S. \& Rubenstein, J. E. Immediate fixed interim prostheses supported by two-stage threaded implants: methodology and results. J. Oral Implantol., 16(2):96-105, 1990.

Testori, T.; Szmukler-Moncler, S.; Francetti, L.; Del Fabbro, M.; Scarano, A.; Piattelli, A. \& Weinstein, R. L. Immediate loading of Osseotite implants: a case report and histologic analysis after 4 months of occlusal loading. Int. J. Periodontics Restorative Dent., 21(5):451-9, 2001.

Wu, A. Y.; Huang, H. L.; Hsu, J. T. \& Chee, W. Biomechanical effects of the implant material and implant-abutment interface in immediately loaded small-diameter implants. Clin. Oral Investig., 18(4):1335-41, 2014.

Yaltirik, M.; Gökçen-Röhlig, B.; Ozer, S. \& Evlioglu, G. Clinical evaluation of small diameter straumann implants in partially edentulous patients: a 5-year retrospective study. J. Dent. (Tehran), 8(2):75-80, 2011.

\author{
Corresponding author: \\ Iván Valdivia Gandur \\ Universidad de Antofagasta \\ Biomedical Department \\ Avenida Angamos 601 \\ Antofagasta \\ CHILE
}

\section{E-mail: ivan.valdivia@uantof.cl}

Received: $26-11-2018$

Accepted: 07-01-2019 